\title{
Penerapan Data Mining dalam pengelompokan Bibit Padi Ungggul Berdasarkan Minat Beli Konsumen Pada PT.Sang Hyang Seri Regional IV Deli Serdang dengan Menggunakan Metode Clustering Algoritma K-Means
}

\author{
Suardi Yakub \\ Program Studi Sistem Informasi, STMIK Triguna Dharma
}

\begin{tabular}{|c|c|}
\hline Article Info & " ABSTRACT \\
\hline $\begin{array}{l}\text { Article history: } \\
\text { Received May } 13^{\text {th }}, 2018 \\
\text { Revised July } 22^{\text {th }}, 2018 \\
\text { Accepted Aug } 05^{\text {th }}, 2018\end{array}$ & $\begin{array}{l}\text { Perbedaan antara benih unggul dengan benih padi tidak unggul terletak pada } \\
\text { proses sertifikasi, dimana benih bibit unggul di proses dan di pelihara } \\
\text { sedemikian rupa sehingga tingkat kemurnian varietas dapat terpelihara dan } \\
\text { memenuhi standar mutu benih yang ditetapkan serta telah di sertifikasi oleh } \\
\text { Balai Pengawasan dan Sertifikasi Benih (BPSB). Sedangkan benih yang tidak } \\
\text { unggul merupakan benih dari varietas lokal atau dari hasil penangkaran sendiri }\end{array}$ \\
\hline $\begin{array}{l}\text { Keyword: } \\
\text { Bibit Unggul } \\
\text { Data Mining } \\
\text { K-Means }\end{array}$ & $\begin{array}{l}\text { yang telah dipilih dan dianggap memenuhi syarat untuk dijadikan benih padi } \\
\text { oleh petani tanpa melalui proses pengawasan dan sertifikasi dari BPSB. } \\
\text { Pengguna bibit padi unggul mendatangkan banyak keuntungan diantaranya } \\
\text { meningkatkan mutu hasil yang nantinya berpengaruh terhadap peningkatan } \\
\text { pendapat petani. } \\
\text { Untuk membantu dalam proses pencarian maka digunakan metode K-Means } \\
\text { yang dipergunakan untuk mengelompokan data nonhierarki (sekatan) yang } \\
\text { mempartisi data yang ada kedalam dua bentuk atau kelompok. Ada pun tujuan } \\
\text { pengelompokan data ini adalah untuk meminimalkan fungsi objektif yang di } \\
\text { set dalam proses pengelompokan yang pada umumnya berusaha } \\
\text { meminimalkan variasi didalam suatu kelompok }\end{array}$ \\
\hline
\end{tabular}

Copyright () 2018 STMIK Triguna Dharma. All rights reserved.

\author{
First Author \\ Nama : Suardi Yakub, SE, S.Kom, MM \\ Program Studi : Sistem Informasi STMIK Triguna Dharma \\ E-Mail
}

\section{PENDAHULUAN}

Indonesia merupakan Negara dengan jumlah penduduk terpadat, setiap tahunnya jumlah penduduk di Indonesia terus meningkat dan peningkatan jumlah penduduk diikuti oleh peningkatan konsumsi beras nasional. Penduduk Indonesia mengkonsumsi beras sebagai makanan pokok. Produksi pangan harus terus ditingkatkan bagi pemenuhan kebutuhan pangan nasional. Peningkatan produksi tanaman pengan khususnya padi harus sejalan dengan laju pertumbuhan penduduk Indonesia agar pemenuhan kebutuhan pangan tercapai.

Perbedaan antara benih unggul dengan benih padi tidak unggul terletak pada proses sertifikasi, dimana benih bibit unggul di proses dan di pelihara sedemikian rupa sehingga tingkat kemurnian varietas dapat terpelihara dan memenuhi standar mutu benih yang ditetapkan serta telah di sertifikasi oleh Balai Pengawasan dan Sertifikasi Benih (BPSB). Sedangkan benih yang tidak unggul merupakan benih dari varietas lokal atau dari hasil penangkaran sendiri yang telah dipilih dan dianggap memenuhi syarat untuk dijadikan benih padi oleh petani tanpa melalui proses pengawasan dan sertifikasi dari BPSB. Pengguna bibit padi unggul mendatangkan banyak keuntungan diantaranya meningkatkan mutu hasil yang nantinya berpengaruh terhadap peningkatan pendapat petani. PT. Sang Hyang Seri (Persero) merupakan salah satu produsen benih padi yang telah berkembang di Indonesia dan merupakan penyumbang benih bagi pemenuhan

Kebutuhan benih unggul nasional. PT. SHS didirikan oleh pemerintah pada tahun 1971 dengan status semiswasta sebagai Badan Usaha Milik Negara (BUMN) untuk mendampingi balai -balai benih dalam memproduksi benih. Salah satu lokasi penangkaran benih padi PT. Sang Hyang Seri terletak di Tanjung Morawa, Kabupaten Deli Serdang, Sumatera Utara. Data mining adalah serangkaian proses untuk mengenali nilai tambah berupa informasi yang selama ini tidak diketahui secara manual dari suatu basis data dengan 
menggunakan penggalian pola-pola dari data dengan tujuan untuk memanipulasi data menjadi informasi yang lebih berharga yang diperolah denagan cara mengekstraksi dan mengenali pola yang penting atau menarik data yang terdapat dalam basis data. Untuk membantu dalam proses pencarian maka digunakan metode K-Means yang dipergunakan untuk mengelompokan data nonhierarki (sekatan) yang mempartisi data yang ada kedalam dua bentuk atau kelompok. Ada pun tujuan pengelompokan data ini adalah untuk meminimalkan fungsi objektif yang di set dalam proses pengelompokan yang pada umumnya berusaha meminimalkan variasi didalam suatu kelompok

\section{LANDASAN TEORITIS}

\subsection{Bibit Padi}

Benih merupakan salah satu komponen utama yang berperan penting dalam peningkatan kualitas produk padi, karenanya penggunaan benih varietas unggul yang bermutu ( berlabel) sangat dianjurkan. Hal ini terkait dengan sifat-sifat yang dimiliki oleh varietas unggul, antara lain: berdaya hasil tinggi, tahan terhadap hama penyakit, dan rasa nasi enak (pulen). Faktor yang mempengaruhi produksi benih padi yaitu dengan adanya ketersediaan benih unggul bermutu tinggi bagi petani dalam melakukan kegiatan usaha tani merupakan syarat penting dalam peningkatan hasil dan kualitas produksi. Benih yang memiliki mutu baik sangatlah diperlukan oleh petani maupun penangkaran benih. Agar petani maupun pengkaran benih tidak merasa dirugikan serta mereka memiliki jaminan kualitas atas benih yang digunakannya, maka diajurkan menggunakan benih unggul sangatlah penting bagi benih unggul sudah ditetapkan kelas-kelas benih unggul

Menurut Sadjad (1993) menyatakan bahwa Benih bermutu harus memenuhi criteria 7 tepat yaitu tepat varietas, tepat mutu, tepat jumlah, tepat waktu, tepat tempat, tepat harga dan tepat pelayanan. Hasil benih ini diberi sertifikat, sehingga dinamakan benih bersertifikat. Benih bersertifikat adalah benih yang proses produksinya menerapkan cara dan persyaratan tertentu sesuai dengan ketentuan standar mutu benih Balai Pengawasan dan Sertifikasi Benih (BPSB) melalui label benih bersertifikat..

\subsection{Data Mining}

Data Mining adalah bidang yang sepenuhnya menggunakan apa yang dihasilkan oleh data warehouse, bersama dengan bidang yang menangani masalah pelaporan dan manajemen data. Sementara, data warehouse sendiri bertugas untuk menarik /meng-query data dari basis data mentah untk memberikan hasil data yang nantinya digunakan oleh bidang yang menangani manajemen, pelaporan, dan data mining. Dengan data mining inilah, penggalian informasi baru dapat dilakukan dengan bekal data mentah yang diberikan oleh data warehouse.

Hasil yang diberikan oleh ketiga bidang tersebut berguna untuk mendukung aktivitas bisnis cerdas (business intelligence). Pekerjaan yang berkaitan dengan data mining dapat dibagi menjadi empat kelompok, yaitu model prediksi (prediction modelling), analisis kelompok (cluster analysis), analisis asosiasi (association analysis), dan deteksi anomaly (anomaly detection).

\subsection{K-Means}

K-Mean merupakan salah satu metode pengelompokan data nonhierarki (sekatan) yang berusaha mempartisi data yang ada kedalam bentuk dua atau lebih kelompok. Metode ini mempartisi data ke dalam kelompok sehinggah data berkarakteristik sama di masukan ke dalam satu kelompok yang sama dan data yang berkarakteristik berbeda dikelompokan kedalam kelompok yang lain. Adapun tujuan pengelompokan data ini adalah untuk meminimalkan fungsi objektif yang diset dalam pparoses pengelompokan, yang pada umumnya berusaha meminimalkan variasi didalam suatu kelompok dan memaksimalkan variasi antar kelompok.

Lokasi sentroid (titik pusat) setiap kelompok yang diambil dari rata-rata (mean) semua nilai data pada setiap fitur nya harus dihitung kembali. Jika M menyatakan jumlah data dalam sebuah kelompok, $i$ menyatakan fitur ke- $i$ dalam sebuah kelompok, dan $p$ menyatakan dimensi data, untuk enghitung sentriod fitur ke- $i$ digunakan formula :

$$
C_{i=\frac{1}{M} \sum_{j=1}^{M} X_{j}}
$$

Formula tersebut dilakukan sebanyak $p$ dimensi sehingga $i$ mulai dari 1 sampai $p$. Menurut eko prasetyo, 2012:179 ada beberapa cara yang dapat digunakan untuk mengukur jarak data kepusat kelompok, diantaranya Euclidean (Bezdek,1981) Manhattan/city block (miyamoto dan agusta,1995), dan Minkowsky (Miyamoto dan Agusta,1995). Masing-masing cara mempunyai kelebihan dan kekurangan. Pengukuran jarak pada ruang jarak (distance space) Euclidean menggunakan formula:

$$
\mathrm{D}\left(\mathrm{X}_{2}, \mathrm{X}_{1}\right)=\left\|\mathrm{X}_{2}-\mathrm{X}_{1}\right\|_{2}=\sqrt{\sum_{j=1}^{P}\left|x_{2 j}-x_{1 j}\right|^{2}}
$$

D adalah jarak antar data x2 dan x1, dan | . | adalah nilai mutlak. Pengukuran jarak pada ruang jarak Manhattan menggunakan formula. 


$$
\mathrm{D}\left(\mathrm{X}_{2}, \mathrm{X}_{1}\right)=\left\|\mathrm{X}_{2}-\mathrm{X}_{1}\right\|_{2}=\sum_{j=1}^{p}\left|x_{2 j}-x_{1 j}\right|
$$

Pengukuran jarak pada ruang jarak Minkowsky menggunakan formula.

$$
\mathrm{D}\left(\mathrm{X}_{2}, \mathrm{X}_{1}\right)=\left\|\mathrm{X}_{2}-\mathrm{X}_{1}\right\|_{2}=\sqrt{\sum_{j=1}^{P}\left|x_{2 j}-x_{1 j}\right| \lambda}
$$

$\lambda$ adalah parameter jarak Minkowsky. Secara umum, $\lambda$ merupakan parameter penentu dalam karateristik jarak. Jika $\lambda=1$ ruang jarak pada Minkowsky sama dengan Manhattan. Jika $\lambda=2$, ruang jaraknya akan sama dengan Euclidean, jika $\lambda=\infty$, ruang jarak nya akan sama dengan ruang jarak Chebyshev. Namun demikian, cara yang paling banyak digunakan Euclidean dan Manhattan. Euclidean menjadi pilihan jika kita ingin memberikan jarak terpendek antara dua titik (jarak lurus), seperti yang ditunjukan, sedangkan Manhattan memberikan jarak terjauh pada dua data. Manhattan juga sering digunakan karena kemampuannya dalam mendeteksi keadaan khusus, seperti keberadaan outlier, dengan lebih baik.

\section{ANALISIS DAN HASIL}

Untuk menguji kebenaran dari hasil pengolahan data yang dikerjakan secara manual pada Bab III tersebut digunakanlah software Microsoft Visual Studio 2008. Berikut ini adalah tahapan dari pengaplikasian Data Mining dengan menggunakan metode K-Means dalam menentukan persediaan stok bibit padi unggul pada PT Sang Hyang Seri Medan :

1. Pertama kali menjalankan aplikasi maka akan tampil menu utama dimana menu pada menu utama masih belum dapat digunakan karena pengguna belum melakukan login kesistem. Dalam form menu utama terdapat dua tampilan yaitu menu Home dan Aplikasi, menu home digunakan untuk menampung menu login, keluar program, tentangsistem, dan tentang programmer. Berikut ini adalah tampilan form utama beranda :

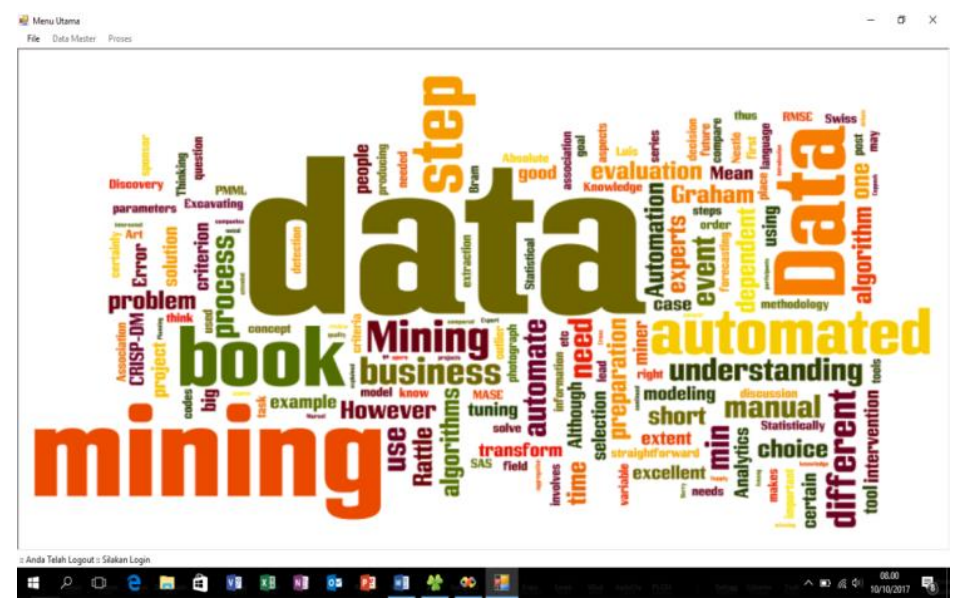

Gambar 1 Tampilan Interface Form MenuUtama

2. Interface Form Login

Tampilan form login dapat dipanggil ketika pengguna memilih menu home dan terdapat button login. Berikut ini adalah gambar tampilan formlogin;

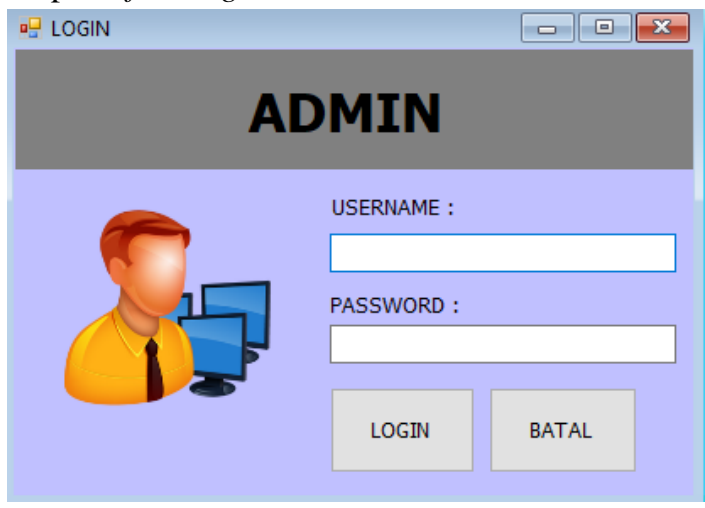

Gambar 2 Tampilan Interface Form Login 
Dari gambar tersebut diatas terdapat dua textbox yang berfungsi sebagai tempat untuk melakukan inputan user name serta password dan dua button yang berfungsi untuk menjadi tombol login dan tombol batal login.

3. Form masukan interface sistem untuk Input Data Penjualansebagai berikut :

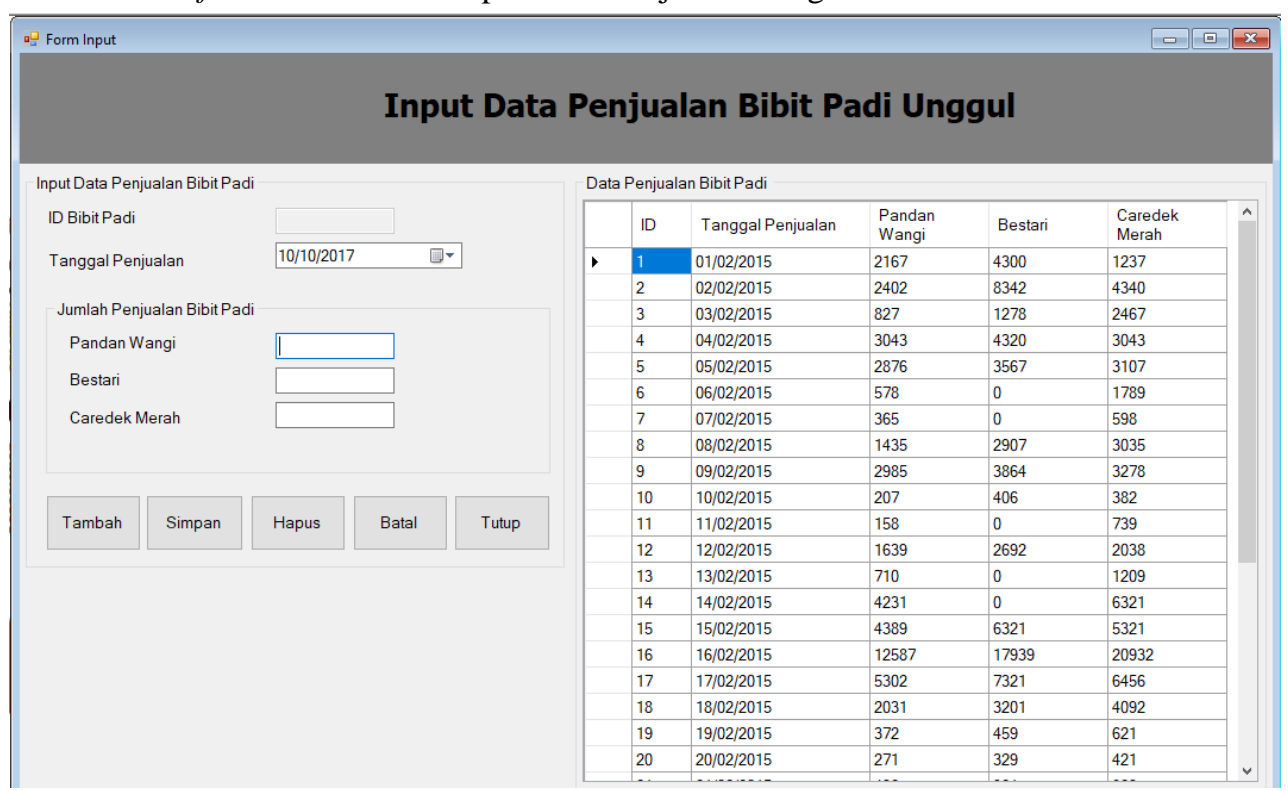

Gambar 3 Tampilan Interface Form Input Data Penjualan

Dari gambar diatas terdapat lima buah textbox yang berfungsi sebagai tempat menampung data yang nantinya akan di input kedalam database kemudian terdapat lima button yang digunakan sebagai perintah untuk melakukan pengolahan data seperti simpan, hapus, ubah, dantutupform.

4. Selanjutnya tampilan interface formhasil perhitunganK-Means sebagai berikut :

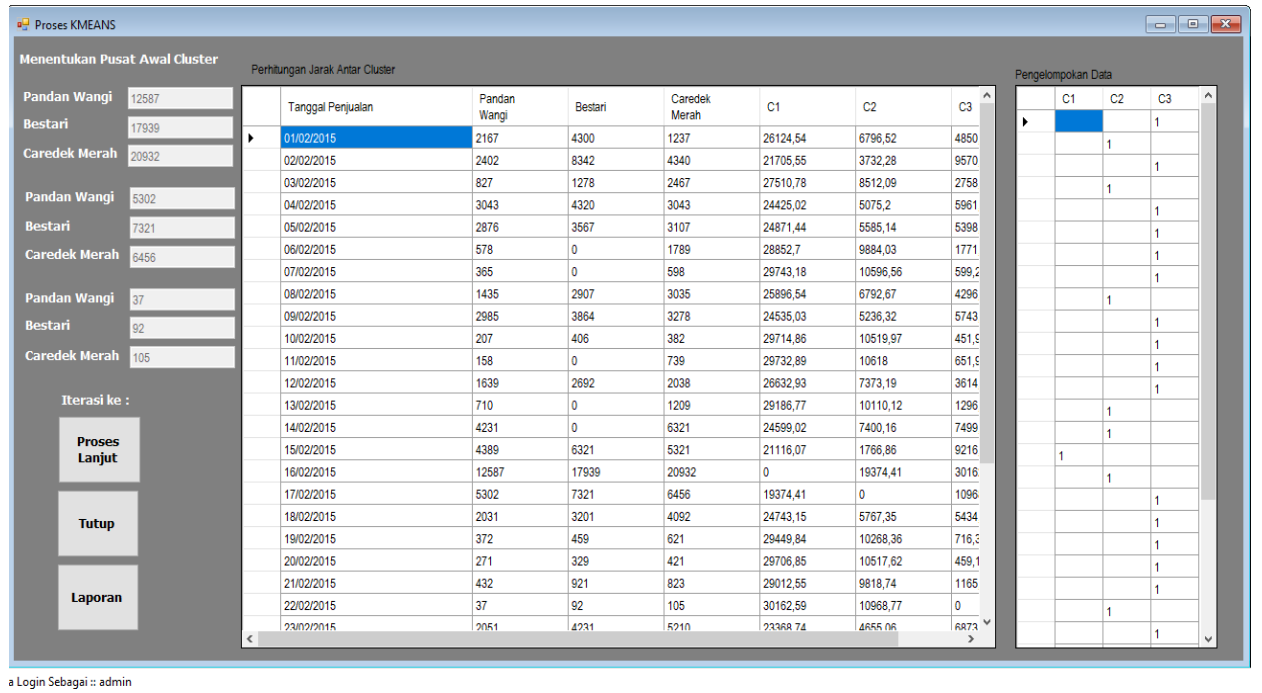

Gambar 4 Tampilan Interface Form Hasil PerhitunganMetode K-Means

Dari gambar diatas terdapat Sembilan textbox yang nantinya digunakan untuk menampung nilai cluster kemudian terdapat tombol sebanyak tiga buah yang masing-masing digunakan untuk melakukan proses perhitungan metode $K$-Means menutup program dan melakukan pencetakan laporan perhitungan $K$ Means.

Setelah melakukan proses implementasi, proses selanjutnya adalah uji coba dengan tujuan untuk mengetahui bahwa hasil perancangan di bab III sesuai dengan hasil yang ditampilkan pada aplikasi. Dalam melakukan pengujian maka dibutuhkan data untuk menjadi bahan yang digunakan dalam perhitungan algoritma K-Means. Adapun data yang dibutuhkan dalam perhitungan algoritma K-Means yaitu : 
1. Tampilan Form Input Data Penjualan

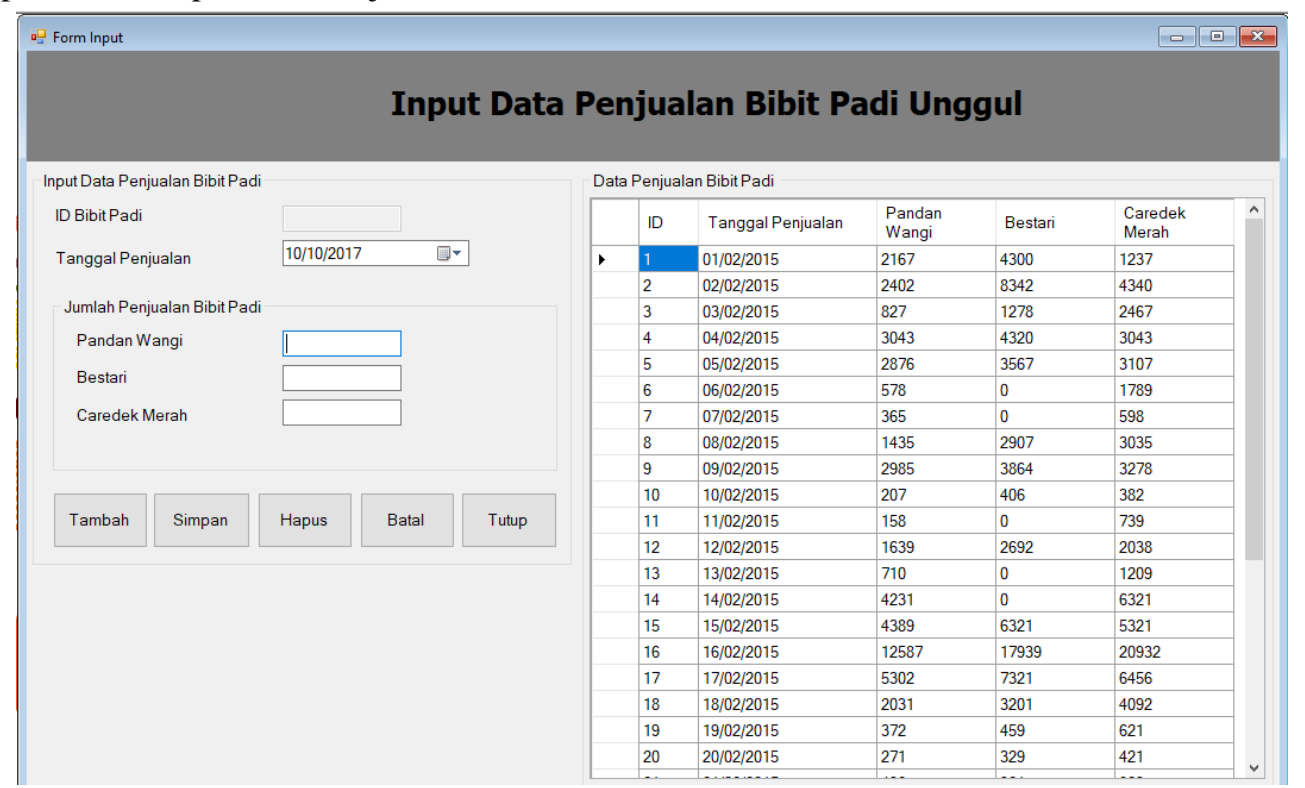

Gambar 5 Tampilan Interface Form Input Data Penjualan

2. Tampilan Form Proses Data MetodeK-Means.

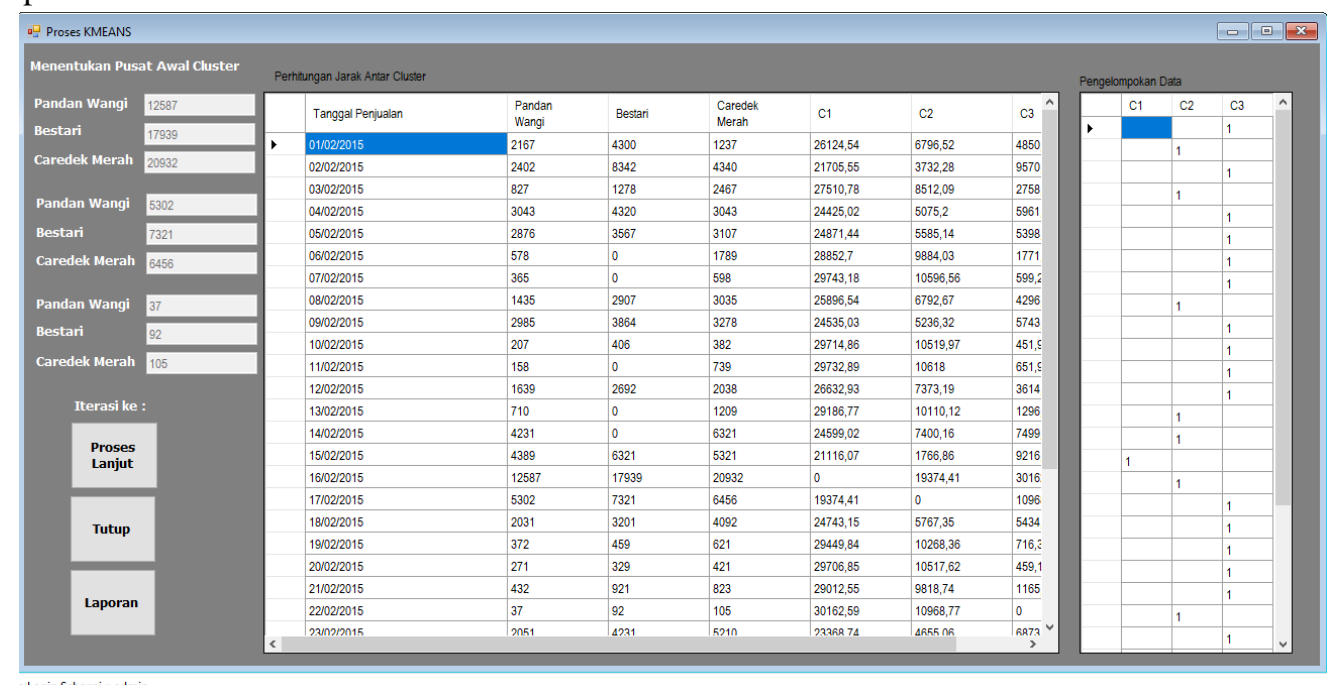

Gambar 6 Tampilan Interface Form Proses

\section{Tampilan Form Laporan}

Setelah melakukan pengujian, untuk hasil/output berupa nilai hasil perhitungan dan keputusan yang diberikan sistem, bentuk laporan hasil perhitungan algoritma $K$-Means adalahsebagai berikut 


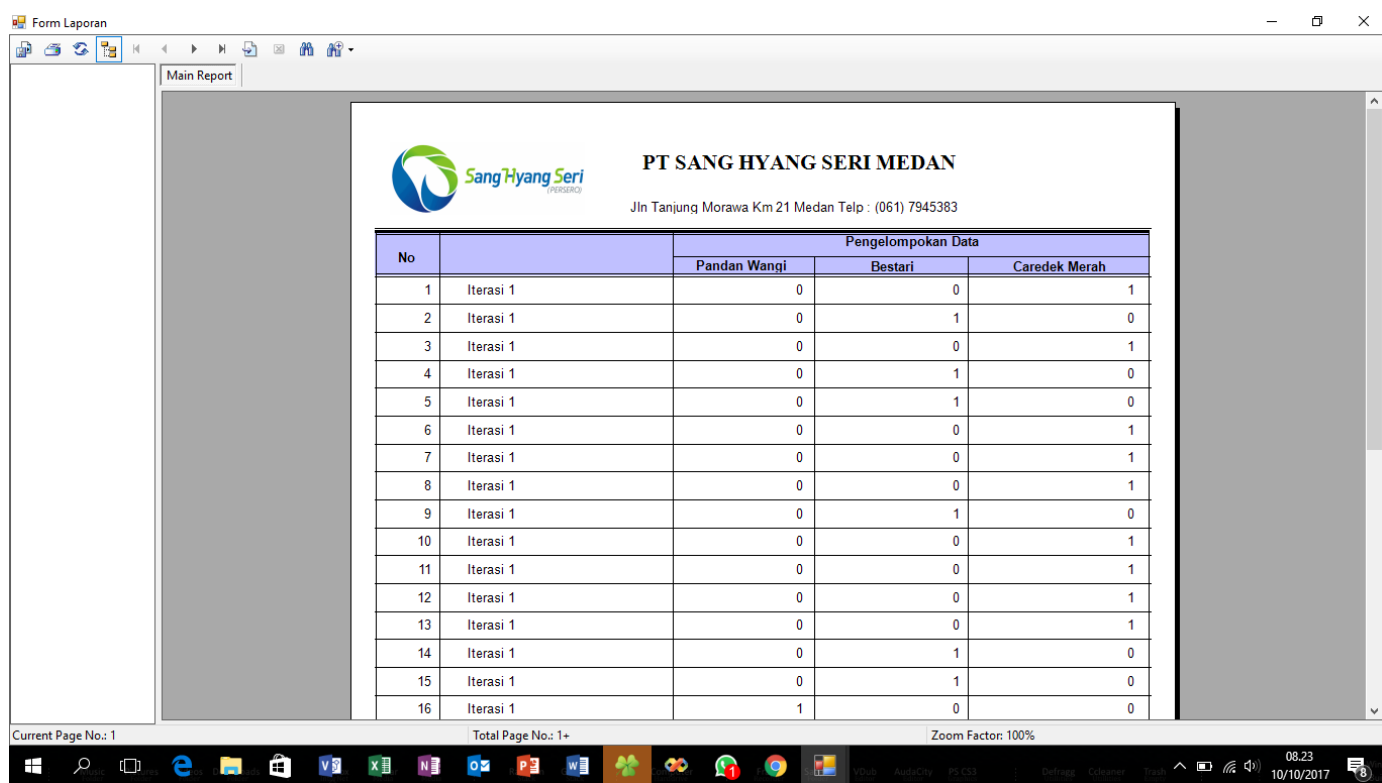

Gambar 7 Tampilan Interface Form LaporanPerhitunganMetodeK-Means

\section{KESIMPULAN}

Dari hasil pembahasan pada bab sebelumnya dan pengamantan yang telah dilakukan maka dapat diambil kesimpulan diantaranya adalah sebagai berikut:

1 Sistem yang telah dibangun ini dapat menganalisis data penjualan Bibit Unggul dengan menerapkan metode K-Means.

2 Dapat menerapkan hasil perhitungan dengan metode K-Means dalam pengelolaan data persediaan Bibit Padi Pada PT.Sang Hyang Seri.

3 Dapat mengimplementasikan Metode K-Means dalam sebuah sistem yang nantinya akan diguanakan untuk menganalisis data penjualan Bibit Padi.

\section{DAFTAR PUSTAKA}

Prasetyo,E.2012. Data Mining Konsep dan Aplikasi Menggunakan Matlab,Yogykarta : Andi Offset.

Sadjad, Syamsul. 1993. Dari Benih Kepada Benih. PT.Gramedia Widiasarana Indonesia. Jakarta.

Rosa,A.S., \& M. 2013. Rekayasa Perangkat Lunak Terstuktur dan Berorientas Objek. Bandung : Informatika

Sulindawaty, Fathoni, M (Agustus 2010). Pengantar analisa Perancangan Sistem Saintikom, 9(2), 491-508

Hendrayudi (Maret 2011) Dasr-dasar Pemrograman Microsoft Visual Basic 2008. Bandung

\section{BIOGRAFI PENULIS}

\begin{tabular}{|l|l|}
\hline & $\begin{array}{l}\text { Suardi Yakub, SE, S.Kom, MM merupakan Dosen Tetap STMIK Triguna Dharma yang aktif } \\
\text { mengampu mata kuliah Prinsip Manajemen Bisnis, Techno Enterpreuner, Metode Penelitian, } \\
\text { Teknik Pemasaram Statistika, Akuntansi dan Komputer Akuntansi. Pria kelahiran Pariaman 06 } \\
\text { April } 1966 \text { ini saat ini menduduki jabatan Wakil Ketua II Bidang Keuangan. Tamat S1 dan S2 di } \\
\text { Universitas Islam Sumatera Utara bidang manajemen, dan beliau mengambil pendidikan kembali } \\
\text { pada bidang ilmu komputer di Sekolah Tinggi Manajemen Informatika dan Komputer ITMI } \\
\text { Medan }\end{array}$ \\
\hline
\end{tabular}

